\title{
How to image cell adhesion on soft polymers?
}

\author{
Silke Seyock, Vanessa Maybeck, Andreas Offenhäusser
}

Institute of Complex Systems (ICS-8/PGI-8), Forschungszentrum Jülich, 52428 Jülich, Germany

Email: a.offenhauesser@fz-juelich.de

\begin{abstract}
Here, we present a method to investigate cell adhesion on soft, non-conducting polymers that are implant candidate materials. Neuronal cells were grown on two elastomers (polydimethylsiloxane (PDMS) and Ecoflex ${ }^{\circledR}$ ) and prepared for electron microscopy. The samples were treated with osmium tetroxide $\left(\mathrm{OsO}_{4}\right)$ and uranylacetate ( $\left.\mathrm{UrAc}\right)$. Best results can be achieved when the polymers were coated with a thin iridium layer before the cell culture. This was done to emphasize the usage of soft polymers as supports for implant electrodes. A good contrast and the adhesion of the cells on soft polymers could be visualized.
\end{abstract}

Keywords focused ion beam, cell interface, PDMS, elastomers

\section{Introduction}

The state of the art to treat neuronal degeneration like Parkinson's disease is deep brain stimulation (DBS). Most electrodes for DBS are made of polyurethane and platinum-iridium electrodes. ${ }^{1}$ Polyurethane's Young's modulus is between $10 \mathrm{MPa}$ and $1000 \mathrm{MPa} .{ }^{2} \mathrm{It}$ is more flexible than metals and not only protects the brain from direct contact with the hard wires connecting the electrodes but also electrically insulates these wires. Though it alleviates symptoms, electrode implantation causes a direct inflammatory response and later a chronic response from the body. ${ }^{3}$ One approach to reduce this response is to use softer support materials that can adapt better to soft tissue (Young's modulus $1 \mathrm{kPa}$ to $180 \mathrm{kPa}^{4,5}$ ). This also improves close contact between devices and cells. A general trend towards soft implant materials can be observed in the literature, increasing by two orders of magnitude since 1980. This increased use of soft materials raises new challenges in investigating how neurons interact with the substrate. Not only for brain implants but also for other implants, like the cochlear implant, it is useful to investigate softer electrode materials.

Neuronal cell culture is used to validate implant materials. The focus of this study is how the interface between neurons and soft materials (PDMS and Ecoflex ${ }^{\circledR}$ ) can be studied. PDMS, for example, has a known biocompatibility and is already used in implant tests. ${ }^{6}$ Electron microscopy techniques are used, including focused ion beam (FIB) milling to view how cells adhere to soft substrates. The major problem is that the polymers are mostly non-conductive and difficult to cut and image using a FIB. They exhibit high charging effects and react with the ion beam. ${ }^{7,8}$ To overcome these problems, we present a staining protocol (as can be seen in Figure 1a) for the polymers to increase contrast and stability.

\section{Methods}


2.1 Sample preparation- The silicone elastomer PDMS (Sylgard 184 Dow Corning) was mixed 1:10 (curing agent : base). The two components of the platinum-catalyzed silicones Ecoflex $5^{\circledR}$ and Ecoflex $0-10^{\circledR}$ (both Smooth-on) were mixed 1:1. The PDMS samples were cured for $4 \mathrm{~h}$ at $60^{\circ} \mathrm{C}$, Ecoflex $5^{\circledR}$ for $5 \mathrm{~min}$ at room temperature, and Ecoflex $0-10^{\circledR}$ for $4 \mathrm{~h}$ at room temperature. After curing all samples were sterilized for 30 min with UV and cut into small blocks.

2.2 Sample coating-Before cell culture the samples were micro contact printed with poly-D-lysine $(0.01 \mathrm{mg} / \mathrm{ml})$, extracellular cell matrix $(0.0924 \mathrm{mg} / \mathrm{ml})$, and gelatin $(0.2 \mathrm{mg} / \mathrm{ml})$ in Gey's balanced salt solution as described in ${ }^{9}$. Briefly, PDMS stamps were incubated for $20 \mathrm{~min}$ in the solution on ice. Stamps were then dried with nitrogen and placed onto the samples for $20 \mathrm{~min}$.

2.3 Cell culture- Primary cortical neurons from E18 Wistar rats were seeded on the samples at 260 cells per $\mathrm{mm}^{2}$ in $1 \mathrm{ml}$ of Neurobasal Medium (Life Technologies, supplemented with 1\% B27 (Gibco), $0.05 \mathrm{mM} \mathrm{L-glutamine}$, and $50 \mu \mathrm{g} / \mathrm{ml}$ gentamicin). One hour after seeding, the medium was changed. The cells were incubated at $5 \% \mathrm{CO}_{2}, 100 \%$ humidity, at $37^{\circ} \mathrm{C}$ for 15 days and fed twice per week by exchanging half the medium.

2.4 Staining-Samples were washed with phosphate-buffered saline (PBS) and fixed for $10 \mathrm{~min}$ with $3.2 \%$ glutaraldehyde in PBS. After washing with PBS and MilliQ, they were treated with $1 \% \mathrm{OsO}_{4}$ in cacodylate buffer (Morphisto) for $2 \mathrm{~h}$ on ice. Samples were washed with MilliQ and left for $30 \mathrm{~min}$ in $1 \%$ tannic acid (Electron Microcopy Sciences) in MilliQ. Post fixation was done overnight in $2 \%$ UrAc (Polyscience) in Bidest. After washing again with MilliQ, the samples were stepped to $100 \%$ ethanol as described in ${ }^{10}$. To preserve cells for SEM, they were embedded in epoxy-resin by stepping from pure ethanol to pure resin as described previously. ${ }^{11}$

2.5 FIB cuts- The samples were glued to a SEM stub using silver glue (Plano GmbH). To protect the cells from the ion and electron beams the samples were sputtered for $30 \mathrm{~s}$ at $15 \mathrm{~mA}$ with platinum (a 1-1.5 $\mu \mathrm{m}$ thick layer). The samples were cut with $30 \mathrm{kV}$ and $0.79 \mathrm{nA}$ or $9.3 \mathrm{nA}$, polished with $30 \mathrm{kV}$ and $0.79 \mathrm{nA}$, and imaged at $3 \mathrm{kV}$, with a current of $21 \mathrm{pA}$ to $1.4 \mathrm{nA}$ using a backscattered electron detector. An electron beam scan of $10 \mu \mathrm{m}^{2}$ with $3 \mathrm{kV}$ and $5.5 \mathrm{nA}$ was applied to the samples without cells.

All experiments were performed with the approval of the Landesumweltamt für Natur, Umwelt und Verbraucherschutz Nordrhein-Westfalen, Recklinghausen, Germany (number 84-02.04.2015.A173). If not stated otherwise, all chemicals were purchased from Sigma Aldrich.

\section{Results and Discussion}




\subsection{Soft polymers}

First, we tested how the different materials react to an electron beam. Therefore, PDMS and Ecoflex ${ }^{\circledast}$ samples were sputtered and a $10 \mu \mathrm{m}^{2}$ square was scanned with the electron beam with $3 \mathrm{kV}$ and $5.5 \mathrm{nA}$. Figure $2 \mathrm{a}$ shows all three materials were deformed when the beam was applied. Waves form around the scanned area, especially in the Ecoflex $0-10^{\circledast}$. All three samples show large charging effects and are difficult to focus on. The PDMS and Ecoflex $5^{\circledR}$ both show an underlying, wrinkled structure, which was also observed for PDMS by Moon et al. ${ }^{7,8}$ The softer the material, the more it deforms in the beam and the more difficult it is to image. According to the companies, Ecoflex $0-10^{\circledR}$ has a Young's modulus of $60 \mathrm{kPa}$, Ecoflex $5^{\circledR}$ of $100 \mathrm{kPa}$ and PDMS of $6700 \mathrm{kPa}$.

\section{2 $\mathrm{OsO}_{4^{-}}$PDMS Reaction}

During $\mathrm{OsO}_{4}$ staining, the samples turn from transparent or white to dark (see Figure $1 \mathrm{~b}$ ). PDMS appears darkest, whereas $\mathrm{Ecoflex}^{\circledR}$ samples appear greyish. OsO $\mathrm{O}_{4}$ is a strong oxidant and reacts with PDMS (see Figure 2b), which appears dark blue, as can be seen in the stained samples. We assume that the reactions with the Ecoflex ${ }^{\circledR}$ substrates are similar, as it is also a silicone-based elastomer. The embedding of a heavy metal into the PDMS, further reduces charging effects during SEM imaging. Additionally, it reacts with carbon double bonds and stains lipids in the interior of the cell and its membranes, which become clearly visible. Thus, it is not only possible to image cells on polymer substrates but also to investigate cell organelles and the nucleus.

\subsection{PDMS samples}

Figure 3 a shows a cross-section of a neuron on PDMS. This sample was not treated with $\mathrm{OsO}_{4}$ nor UrAc and thus has poor contrast. It is difficult to focus on the interface.

\subsection{PDMS samples stained with $\mathrm{OsO}_{4}$ and UrAc}

Samples stained with $\mathrm{OsO}_{4}$ and UrAc staining can be seen in Figure $3 \mathrm{~b}$. The contrast is better than without the staining, however some parts of the cell membrane are difficult to focus on. This could be due to an overstaining with $\mathrm{OsO}_{4}$, as the cell is in direct contact with the PDMS which locally increases $\mathrm{OsO}_{4}$ concentration.

\subsection{PDMS samples sputtered with Iridium}

To mimic an electrode on top of PDMS we sputtered samples with iridium for 40s with $15 \mathrm{~mA}$ before culturing. It also improved the contrast as large charging effects were avoided. The idea was that even with a thin layer of iridium the cell is still able to adapt to the softness of the polymer underneath. These samples show the best contrast from cell to substrate (see Figure 3c). Additionally, the cell interior is clearly visible. The membrane of the nucleus, as well as the mitochondrial membrane, can be distinguished from the cytoplasm. An explanation for the good staining is that the metal layer protects the cell from overstaining, as the $\mathrm{OsO}_{4}$ soaked into the PDMS does not diffuse back to the cell. During the first washing steps after the staining it can be observed that the washing solutions turn dark, as they remove redundant $\mathrm{OsO}_{4}$.

\subsection{Ecoflex ${ }^{\circledR}$ samples}


In comparison to the PDMS, the much softer Ecoflex ${ }^{\circledR}$ shows a different behavior. Even stained, it is not possible to FIB mill through the material, as it melts away during cutting. As can be seen in Figure $3 \mathrm{~d}$, no cell structures and also no cell-substrate interface can be imaged.

\section{Conclusions}

The best pictures and the best contrast can be achieved when the polymer samples are sputtered before cells are seeded on top and if samples are additionally treated with $\mathrm{OsO}_{4}$ and UrAc.

The softer the substrate, the more difficult it is to image the cell on top, as can be observed with the soft Ecoflex ${ }^{\circledast}$ samples. The charging effect increases as well.

We present a method to investigate cell adhesion on soft polymers. As these polymers could be used as materials for implants it is interesting to investigate their interaction with cells. We expect this to be of increasing interest for other polymers and cell types.

\section{Acknowledgements}

We thank Andreea Belu for help with the fixation, Bettina Breuer for cell preparation and Elke Brauweiler-Reuters for FIB cuts. Elmar Neumann we would like to thank for the help with the $\mathrm{OsO}_{4}$ reaction. Part of this work was funded within the Helmholtz-CAS Joint Research Group 106.

\section{References}

1 http://professional.medtronic.com/pt/neuro/dbs-md/prod/dbs-lead-model-3387/ (accessed: 22-08-2016)

2

http://www.polyurethanes.basf.de/pu/solutions/us/function/conversions:/publish/content/g roup/Arbeitsgebiete_und_Produkte/Thermoplastische_Spezialelastomere/Infomaterial/elasto Ilan_material_uk.pdf (accessed: 22-08-2016)

3 J. B. Leach, A. K. H. Achyuta and S. K. Murthy, Front. Neuroeng., 2010, 2, 18.

$4 \quad$ O. Clatz, H. Delingette, I.-F. Talos, A. J. Golby, R. Kikinis, F. A. Jolesz, N. Ayache and S. K. Warfield, IEEE Trans. Med. Imaging, 2005, 24, 1417-1427.

5 P. Schiavone, F. Chassat, T. Boudou, E. Promayon, F. Valdivia and Y. Payan, Med. Image Anal., 2009, 13, 673-678.

6 L. Vaysse, A. Beduer, J. C. Sol, C. Vieu and I. Loubinoux, Biomaterials, 2015, 58, 46-53.

7 M.-W. Moon, S. H. Lee, J.-Y. Sun, K. H. Oh, A. Vaziri and J. W. Hutchinson, Proc. Natl. Acad. Sci., 2007, 104, 1130-1133.

8 M.-W. Moon, S. H. Lee, J.-Y. Sun, K. H. Oh, A. Vaziri and J. W. Hutchinson, Scr. Mater., 2007, 57, 747-750.

9 J. Albers, K. Toma and A. Offenhäusser, Biotechnol. J., 2015, 10, 332-338. 

Wolfrum, Nanoscale, 2015, 7, 9275-9281.

11 A. Belu, J. Schnitker, S. Bertazzo, E. Neumann, D. Mayer, A. Offenhäusser and F. Santoro, J. Microsc., 2016, 263, 78-86.
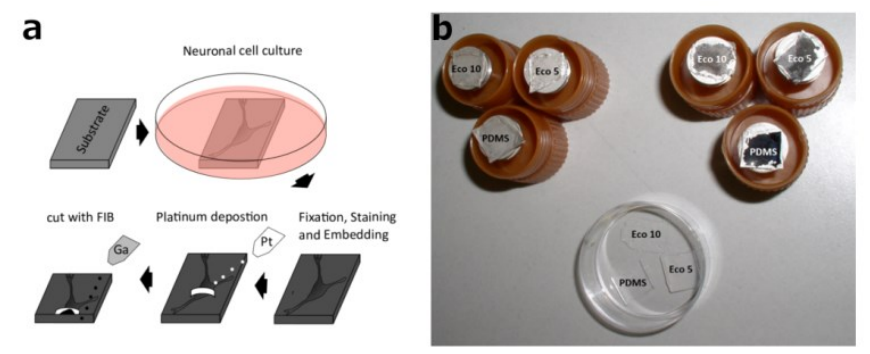

Figure1: a)Schematic of sample production: neuronal cells are cultured on the substrate, then fixed, stained, and embedded. After platinum deposition the sample is cut using a FIB. b) Overview of PDMS, Ecoflex $5^{\circledR}$ and Ecoflex $0-10^{\circledR}$ samples, bottom: samples before treatment, left top: samples after glutaraldehyde treatment, right top: samples with glutaraldehyde treatment, $\mathrm{OsO}_{4}$ and $\mathrm{UrAc}$ staining.
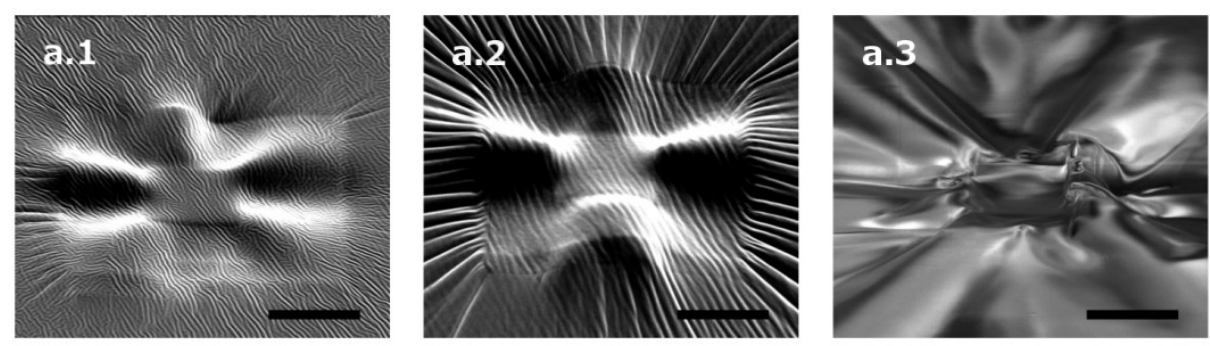

b
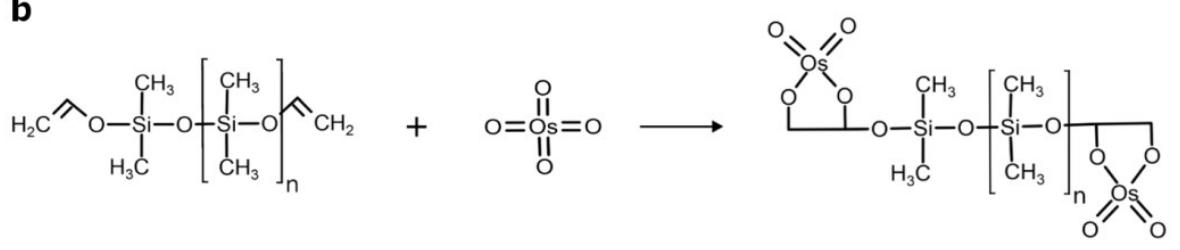

Figure 2: a) Reaction of sputtered samples without cells, after electron beam imaging, scale bars 10 $\mu \mathrm{m}$ a.1) PDMS a.2) Ecoflex $5^{\circledR}$ a.3) Ecoflex $0-10^{\circledR}$. b) Reaction equation of $\mathrm{PDMS}$ with $\mathrm{OsO}_{4}, \mathrm{OsO}_{4}$ binds to the double bonds of PDMS. 


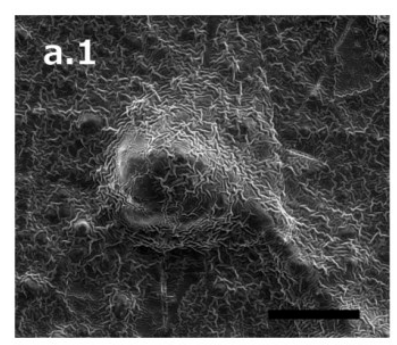

\section{a.2}
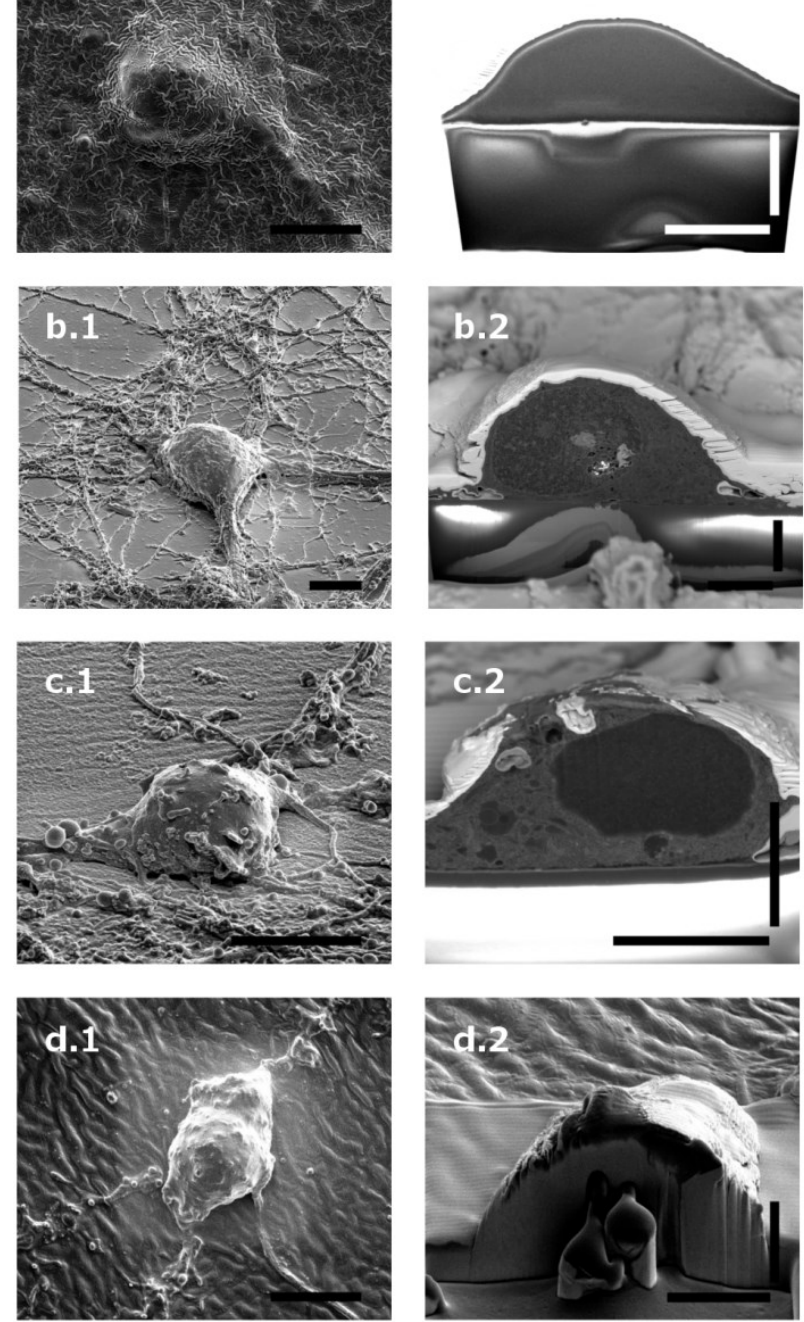

Figure 3: Left side: neuronal cells, top view, scale bars $10 \mu \mathrm{m}$, right side: cross sections of neurons, scale bars $5 \mu \mathrm{m}$ a) fixed neuron on a PDMS substrate. b) Fixed neuron on a PDMS substrate treated with $\mathrm{OsO}_{4}$ and UrAc. c) Fixed neuron on an Ir sputtered PDMS substrate treated with $\mathrm{OsO}_{4}$ and UrAc. d) Fixed neuron on Ecoflex $0-10^{\circledR}$ treated with $\mathrm{OsO} 4$ and UrAc. 